\title{
Effects Comparison between Endoscopic Papillary Large Balloon Dilatation and Endoscopic Sphincterotomy for Common Bile Duct Stone Removal
}

\author{
Yandong Guo, Chen Li, Shan Lei, and Fachao Zhi \\ Department of Gastroenterology, Guangdong Provincial Key Laboratory of Gastroenterology, Nanfang Hospital, \\ Southern Medical University, Guangzhou 510515, China \\ Correspondence should be addressed to Fachao Zhi; zhifc41532@163.com
}

Received 9 December 2014; Accepted 3 June 2015

Academic Editor: Michel Kahaleh

Copyright (C) 2015 Yandong Guo et al. This is an open access article distributed under the Creative Commons Attribution License, which permits unrestricted use, distribution, and reproduction in any medium, provided the original work is properly cited.

\begin{abstract}
Endoscopic sphincterotomy (EST) is a treatment of choice for stone extraction and is now most frequently used. The study was to compare the efficacy of endoscopic papillary large balloon dilatation (EPLBD) and endoscopic sphincterotomy (EST) for common bile duct stone removal. Trials comparing the effects between EPLBD and EST treatment were searched according to the study protocol. Overall stone removal rate, complete removal rate in 1st session, treatment duration, mechanical lithotripsy using rate, and overall complication rate were compared using risk ratio (RR) and mean difference (MD) and their 95\% confidence interval (CI) via RevMan 5.2 software. For overall stone removal rate, two therapies showed similar effect, but EPLBD showed better overall stone removal rate for stone $>10 \mathrm{~mm}$ in diameter. For complete stone removal rate in 1st session, no difference was found, even for those with stone $>10 \mathrm{~mm}$ in diameter; EPLBD showed longer treatment duration, higher mechanical lithotripsy using rate obvious overall complications rate, and more serious bleeding, whereas there were no significant differences for perforation, hyperamylasemia, pancreatitis, and cholecystitis/cholangitis. EPLBD showed better efficacy in certain conditions compared to EST, however with shortcomings, such as more duration, higher mechanical lithotripsy using rate, more serious overall complications rate, and bleeding.
\end{abstract}

\section{Introduction}

Common bile duct stones are present in about 4-10 percent of patients who have undertaken cholecystectomy [1]. Reported incidence of common bile duct stone varies from $5 \%$ to $11 \%$ at the time of cholecystectomy $[2,3]$. The vast majority of common bile duct stone mainly originates from gallbladder [4]. Its signs and symptoms are variable, ranging from being completely asymptomatic to complications, such as biliary colic, cholangitis, jaundice, or pancreatitis [5].

Endoscopic sphincterotomy (EST), first described in 1974, is a treatment of choice for stone extraction and is now most frequently used [6]. Although EST is relatively safe, it is reported to induce high level of overall complication rates, as well as short-term risks, including bleeding, perforation, and pancreatitis. Endoscopic papillary large balloon dilatation (EPLBD) had been introduced as an alternation for EST to manage the common bile duct stones, for its lower frequency in perforation and hemorrhage [7]. However, in another study comparing these two treatments, EST showed lower pancreatitis occurrence than EPLBD and 2 patients died of pancreatitis because of the EPLBD extraction [8]. It remained as a controversial issue whether EPLBD has a better effect than EST.

In this study, we conducted a meta-analysis to compare the data collected in trials published between 2004 and 2013. Overall stone removal rate, complete stone removal rate in 1st session, treatment duration, mechanical lithotripsy using rate, and overall/each complications rate were compared between the two therapies.

\section{Methods}

2.1. Information Sources and Searches. A search of the literature was conducted for studies that reported the EPLBD versus EST for common bile duct stone removal. 
TABLE 1: Characteristics of the included 10 prospective studies.

\begin{tabular}{|c|c|c|c|c|c|}
\hline Study & Design $^{*}$ & Country & Bile duct stones & Intervention $(n)$ & Dilated balloon catheter \\
\hline Lin et al., 2004 [9] & $\mathrm{D}, \mathrm{S}, \mathrm{R}$ & China & Multiple, mean $=8 \mathrm{~mm}$ & EPLBD (51) or EST (54) & $10-12 \mathrm{~mm}$ \\
\hline Heo et al., 2007 [6] & $\mathrm{D}, \mathrm{S}, \mathrm{R}$ & Korea & Multiple, mean $=16.0-15.0$ & $\begin{array}{l}\text { EST plus EPLBD (100) or EST } \\
(100)\end{array}$ & $12-20 \mathrm{~mm}$ \\
\hline Itoi et al., 2009 [10] & $S$ & Japan & Large & $\begin{array}{l}\text { Small EST plus EPLBD (53) or } \\
\text { EST ( } 48)\end{array}$ & $10-20 \mathrm{~mm}$ \\
\hline $\begin{array}{l}\text { García-Cano et al., } \\
2009 \text { [11] }\end{array}$ & $\mathrm{D}, \mathrm{S}$ & Spain & Multiple, mean $=3 \mathrm{~mm}$ & $\begin{array}{l}\text { EST plus EPLBD (31) or EST } \\
(60)\end{array}$ & $10-20 \mathrm{~mm}$ \\
\hline Kim et al., 2009 [12] & $\mathrm{D}, \mathrm{S}, \mathrm{R}$ & South Korea & Large, $\geq 15 \mathrm{~mm}$ & $\begin{array}{l}\text { Small EST plus EPLBD (27) or } \\
\text { EST (28) }\end{array}$ & $15,16.5$, or $18 \mathrm{~mm}$ \\
\hline Kim et al., 2011 [13] & S & Korea & Large, $\geq 10 \mathrm{~mm}$ & $\begin{array}{l}\text { Small EST plus EPLBD (72) or } \\
\text { EST (77) }\end{array}$ & $12-20 \mathrm{~mm}$ \\
\hline $\begin{array}{l}\text { Stefanidis et al., } 2011 \\
{[14]}\end{array}$ & $\mathrm{D}, \mathrm{S}, \mathrm{R}$ & Greece & Large, $>12 \mathrm{~mm}$ & $\begin{array}{l}\text { Full EST plus EPLBD (45) } \\
\text { or EST plus ML (45) }\end{array}$ & $10-20 \mathrm{~mm}$ \\
\hline Oh and Kim, 2012 [15] & $S, R$ & Korea & Large, $>10 \mathrm{~mm}$ & EPLBD (40) or EST (43) & $10-20 \mathrm{~mm}$ \\
\hline Teoh et al., 2013 [16] & $\mathrm{D}, \mathrm{S}, \mathrm{R}$ & China & Large, $>13 \mathrm{~mm}$ & $\begin{array}{l}\text { Limit EST plus EPLBD (73) or } \\
\text { EST (78) }\end{array}$ & $15 \mathrm{~mm}$ \\
\hline Li et al., 2014 [17] & $S, D$ & China & Multiple, mean $=12.7-13.2$ & $\begin{array}{l}\text { Small EST plus EPBD (232) or } \\
\text { EST (230) }\end{array}$ & $15,16.5$, or $18 \mathrm{~mm}$ \\
\hline
\end{tabular}

${ }^{*}$ D: double blinded; S: single center; R: randomization.

The PubMed, Web of Science, Medline, Science Citation Index, EMBASE, China National Knowledge Infrastructure, Wanfang Database, and China Biomedical Database were searched to identify double blinded research (D, S, R), single center trials (S), and random clinical trials (RCTs published) in the field of common bile duct stone removal between 2004 and 2013. The keywords used in literature searches included the following: bile duct stones, endoscopic sphincterotomy, and endoscopic papillary balloon dilatation.

2.2. Eligibility Criteria and Outcome Measure. The inclusion criteria were the following: (i) the included studies were designed to compare the therapeutic effects of endoscopic sphincterotomy and endoscopic papillary large balloon dilatation or the combination of the two therapeutics and (ii) the publications could be written in any language. Reports of duplicated studies were excluded by examining the author list, parent institution, sample size, and results.

The primary outcome was overall stone removal rate, overall/complete stone removal rate in 1st session, treatment duration, mechanical lithotripsy using rate, and overall/each complications rate.

2.3. Assessment of Study Quality. Two authors (Shan Lei and Chen Li) independently assessed the quality of the included studies according to the descriptions provided by the authors of the included trials. The methodological quality of the trials was assessed based on adequate sequence generation, allocation concealment, blinding, management of incomplete outcome data, and early stopping for benefit [18].

2.4. Study Selection and Data Collection. Two authors (Shan Lei and Chen Li) independently screened titles and abstracts for potential eligibility and the full texts for final eligibility. We extracted the data from the included trials independently for quantitative analyses, and any disagreement was subsequently resolved by discussion. The quantitative data included the country, stone diameters, interventions, and dilated balloon catheter.

2.5. Synthesis of Results. In this meta-analysis, we used a random effect model because of the anticipated variability among trials with regard to patient populations $[19,20]$. The measure of association used in this meta-analysis was the risk ratio $(\mathrm{RR})$ or mean difference $(\mathrm{MD})$ with a $95 \%$ confidence interval (CI). The summary RR with the 95\% CI was calculated by the RevMan 5.2 software using the random or fixed effect model. A statistically significant result was assumed when the 95\% CI did not include one.

Heterogeneity was explored using a Chi-square test; $P<$ 0.05 represents that there is heterogeneity of effect size. In addition, the quantity of heterogeneity was measured using the $I^{2}$ statistic, which calculates the percentage of total variation across studies caused by heterogeneity rather than sampling errors. $I^{2}=25 \%$ was considered as low heterogeneity and $50 \%$ as moderate, while $75 \%$ was considered as high.

\section{Results}

3.1. Literature Search and Population. Fifteen trials were finally identified in the English literature. Two trials were removed after blind review because they did not compare the result of EST and EPLBD, 2 reviews were also excluded, and the data of 1 literature was also excluded for the information being incomplete. Characteristics of the final 10 prospective studies [6, 9-17] are shown in Table 1. Patient numbers with EST and EPLBD treatment were 763 and 769 (Table 1).

3.2. Comparison of the Overall Stone Removal Rate of EPLBD and EST Treatments. The rate ratios for overall stone removal 


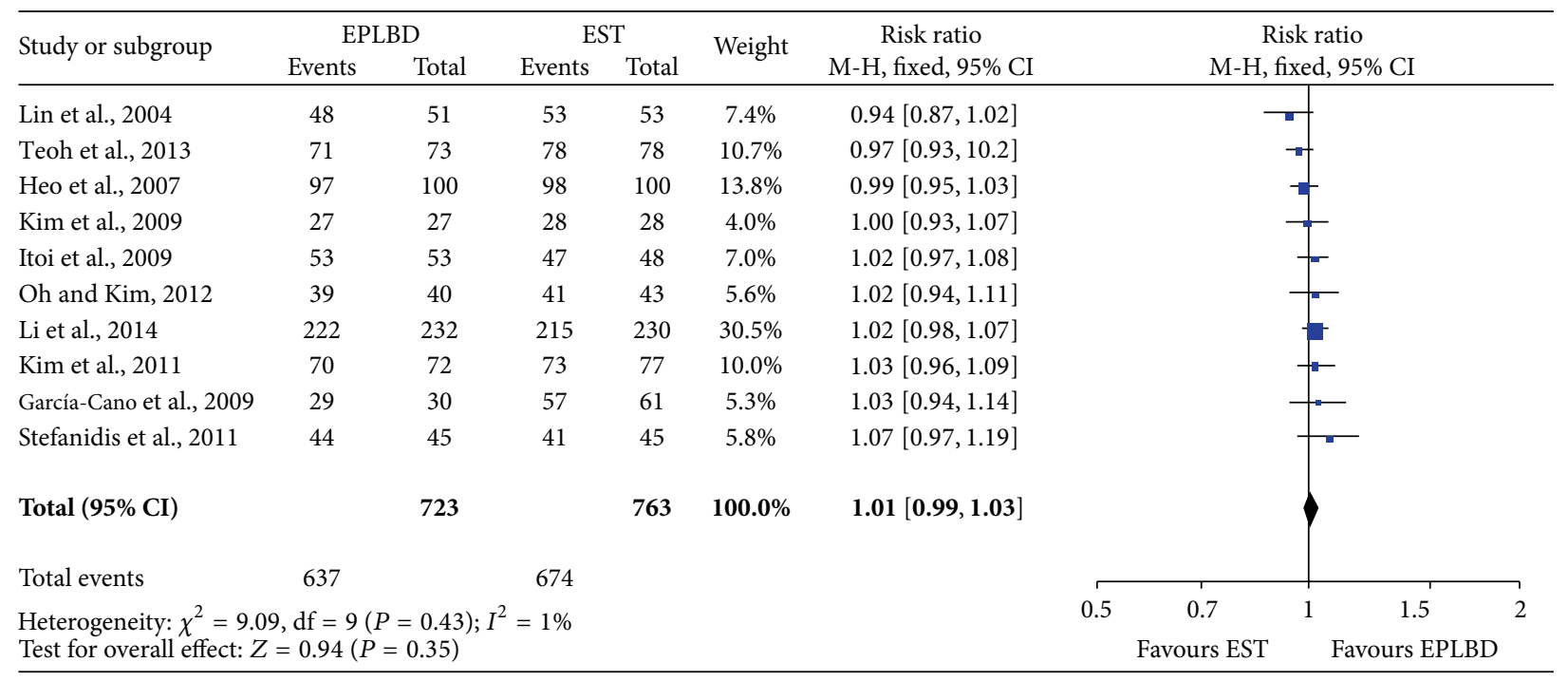

(a)

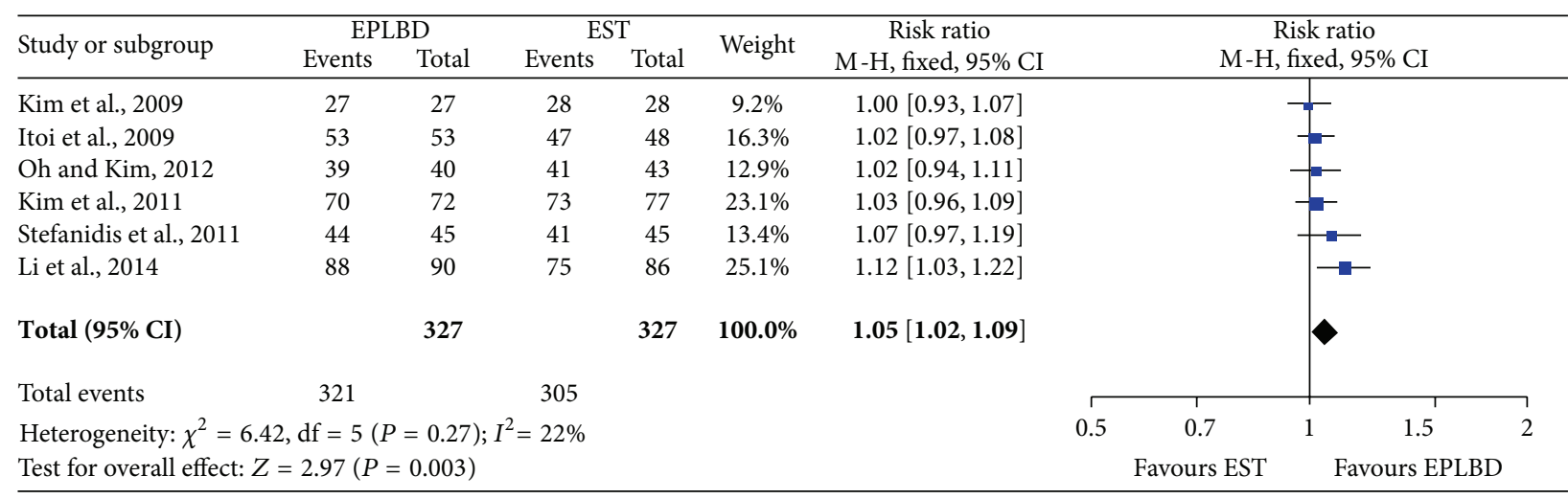

(b)

FIGURE 1: Rate ratio for overall stone removal rate of EPLBD and EST treatment (a) and overall stone removal rate for stone $>10 \mathrm{~mm}$ in diameter (b).

rate for patients taking EPLBD therapies were similar to that of those taking EST therapies (RR: 1.01, 95\% CI: 0.99-1.03; $P=0.35$ ) (Figure 1(a)), but, for the patient with stone $>10 \mathrm{~mm}$ in diameter, the rate ratios for overall stone removal rate of EPLBD were higher than those of EST (RR: 1.05, 95\% CI: 1.02-1.09, $P<0.05$ ) (Figure 1(b)). The result showed that EPLBD had better efficacy than EST method for stones larger than $10 \mathrm{~mm}$ in terms of overall removal rate. The rate ratio for complete stone removal rate in 1st session of EPLBD was similar to that of EST (RR: 1.07, 95\% CI: 0.98$1.16, P=0.11$ ) (Figure $2(\mathrm{a})$ ), and the rate ratio for complete stone $>10 \mathrm{~mm}$ in diameter removal rate in 1 st session for EPLBD and EST was also similar (RR: 1.11, 95\% CI: 0.99$1.24, P=0.08$ ) (Figure 2(b)). Thus, there was no significant difference between the two kinds of treatment in terms of complete stone removal rate in 1st session. In this metaanalysis for complete stone $>10 \mathrm{~mm}$ in diameter removal rate in 1st session, there was apparent heterogeneity $(P=0.01$, $I^{2}=64 \%$ ), so random effect model was used. What is more, for the other outcomes, fixed effect model was used for there was no apparent heterogeneity.
3.3. Comparison for Treatment Duration and Mechanical Lithotripsy Using Rate for EPLBD and EST. There was significant heterogeneity in the assessment of treatment duration $\left(P<0.00001, I^{2}=90 \%\right)$, so random effect model was used. It turned out that the two kinds of treatment were significantly different $(\mathrm{MD}=-5.05,95 \% \mathrm{CI}:-9.55 \sim-0.54, P=0.03$; Figure 3(a)), and EPLBD showed longer treatment duration. Fixed effect model was used for mechanical lithotripsy assessment for no heterogeneity $\left(P=0.13, I^{2}=37 \%\right)$, and the RR value was 0.47 with $95 \%$ CI being between 0.37 and $0.60(P<0.00001$; Figure $3(\mathrm{~b}))$. EPLBD treatment had higher mechanical lithotripsy using rate compared with EST treatment.

3.4. Comparison for Complications Rate for EPLBD and EST. No apparent heterogeneities were detected between the studies in terms of overall complications rate $(P=0.22$, $I^{2}=24 \%$ ) and each complications rate (bleeding: $P=0.11$, $I^{2}=41 \%$; perforation: $P=0.63, I^{2}=0 \%$; hyperamylasemia: $P=0.22, I^{2}=24 \%$; pancreatitis: $P=0.98, I^{2}=0 \%$; cholecystitis/cholangitis: $P=0.64, I^{2}=0 \%$ ); then fixed 


\begin{tabular}{lccccccccc}
\hline Study or subgroup & \multicolumn{2}{c}{ EPLBD } & \multicolumn{2}{c}{ EST } & Weight & \multicolumn{2}{c}{ Risk ratio } \\
M-H, fixed, 95\% CI & & Risk ratio \\
M-H, fixed, 95\% CI
\end{tabular}

(a)

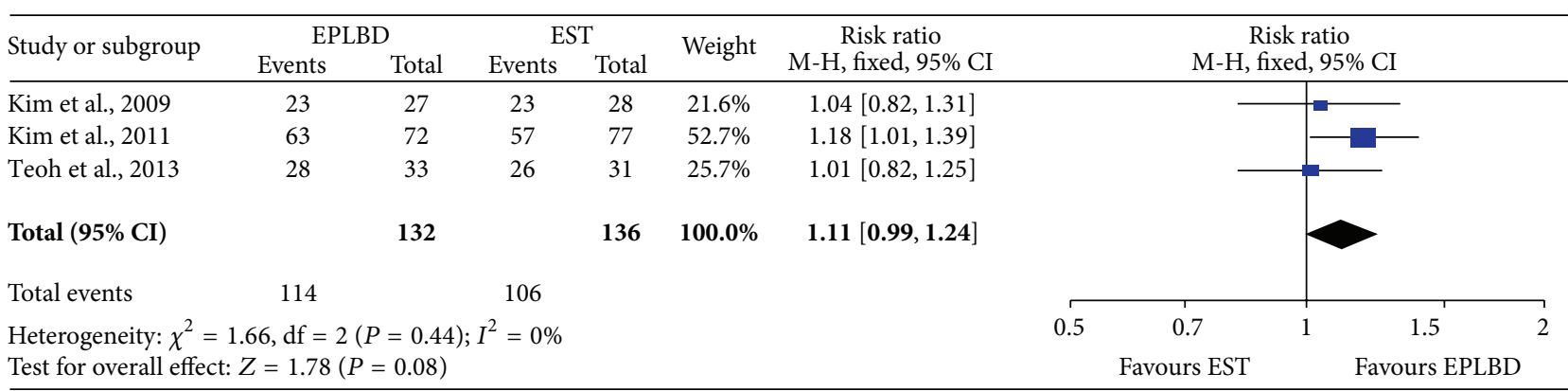

(b)

FIGURE 2: Rate ratio for complete stone removal rate in 1st session of EPLBD and EST treatment (a) and complete stone removal rate in 1st session for stone $>10 \mathrm{~mm}$ in diameter $(\mathrm{b})$.

\begin{tabular}{|c|c|c|c|c|c|c|c|c|c|c|}
\hline \multirow{3}{*}{$\frac{\text { Study or subgroup }}{\text { Teoh et al., } 2013}$} & \multicolumn{2}{|c|}{ EPLBD } & \multirow{2}{*}{ Total } & \multicolumn{2}{|c|}{ EST } & \multirow{2}{*}{ Total } & \multirow{2}{*}{ Weight } & \multirow{2}{*}{$\begin{array}{c}\text { Mean difference } \\
\text { IV, random, 95\% CI }\end{array}$} & \multirow{2}{*}{\multicolumn{2}{|c|}{$\begin{array}{c}\text { Mean difference } \\
\text { IV, random, } 95 \% \text { CI }\end{array}$}} \\
\hline & Mean & SD & & Mean & $\mathrm{SD}$ & & & & & \\
\hline & 24.3 & 12.87 & 73 & 27.2 & 16.9 & 78 & $21.7 \%$ & $-2.90[-7.67,1.87]$ & - & - \\
\hline Li et al., 2014 & 38.6 & 15.5 & 232 & 47.1 & 20.2 & 230 & $24.9 \%$ & $-8.50[-11.79,-5.21]$ & $-1-$ & \\
\hline Itoi et al., 2009 & 32 & 8 & 53 & 40 & 8 & 48 & $25.2 \%$ & $-8.00[-11.12,-4.88]$ & - - & \\
\hline Lin et al., 2004 & 44 & 3 & 51 & 45 & 3 & 53 & $28.2 \%$ & $-1.00[-2.15,0.15]$ & - & \\
\hline Total $(95 \% \mathrm{CI})$ & & & 4.9 & & & 409 & $100.0 \%$ & $-5.05[-9.55,-0.54]$ & & \\
\hline \multicolumn{9}{|c|}{ Heterogeneity: $\tau^{2}=18.42 ; \chi^{2}=31.24, \mathrm{df}=3(P<0.00001) ; I^{2}=90 \%$} & $-10 \quad-5$ & 10 \\
\hline \multicolumn{9}{|c|}{ Test for overall effect: $Z=2.19(P=0.03)$} & Favours EPLBD & Favours EST \\
\hline
\end{tabular}

(a)

\begin{tabular}{|c|c|c|c|c|c|c|c|c|c|c|c|}
\hline \multirow{3}{*}{$\begin{array}{l}\text { Study or subgroup } \\
\text { Itoi et al., } 2009\end{array}$} & \multicolumn{2}{|c|}{ EPLBD } & \multicolumn{2}{|c|}{ EST } & \multirow{3}{*}{$\begin{array}{c}\text { Weight } \\
7.4 \%\end{array}$} & \multirow{3}{*}{$\begin{array}{c}\text { Risk ratio } \\
\text { M-H, fixed, 95\% CI } \\
0.23[0.07,0.75]\end{array}$} & \multirow{2}{*}{\multicolumn{5}{|c|}{$\begin{array}{c}\text { Risk ratio } \\
\text { M-H, fixed, 95\% CI }\end{array}$}} \\
\hline & \multirow{2}{*}{$\begin{array}{c}\text { Events } \\
3\end{array}$} & \multirow{2}{*}{$\begin{array}{c}\text { Total } \\
53\end{array}$} & \multirow{2}{*}{$\frac{\text { Events }}{12}$} & \multirow{2}{*}{$\begin{array}{c}\text { Total } \\
48\end{array}$} & & & & & & & \\
\hline & & & & & & & & 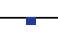 & & & \\
\hline Li et al., 2014 & 28 & 232 & 80 & 230 & $47.3 \%$ & $0.35[0.23,0.51]$ & & & & & \\
\hline Kim et al., 2011 & 6 & 72 & 15 & 77 & $8.5 \%$ & $0.43[0.18,1.04]$ & & & & & \\
\hline Oh and Kim, 2012 & 4 & 40 & 9 & 43 & $5.1 \%$ & $0.48[0.16,1.43]$ & & & & & \\
\hline Lin et al., 2004 & 1 & 51 & 2 & 53 & $1.2 \%$ & $0.52[0.05,5.56]$ & & & & & \\
\hline Teoh et al., 2013 & 21 & 73 & 36 & 78 & $20.5 \%$ & $0.62[0.40,0.96]$ & & & & & \\
\hline Heo et al., 2007 & 7 & 100 & 8 & 100 & $4.7 \%$ & $0.88[0.33,2.32]$ & & & & & \\
\hline Kim et al., 2009 & 9 & 27 & 9 & 28 & $5.2 \%$ & $1.04[0.49,2.21]$ & & & & & \\
\hline Total $(95 \%$ CI $)$ & & 648 & & 657 & $100.0 \%$ & $0.47[0.37,0.60]$ & & & & & \\
\hline Total events & 79 & & 171 & & & & & & & & \\
\hline Heterogeneity: $\chi^{2}=$ & $16, \mathrm{df}=$ & $=0.13)$ & $2=37 \%$ & & & & 0.15 & 0.2 & 1 & 5 & 20 \\
\hline Test for overall effe & $=6.23($ & 0.00001 & & & & & & rs EPI & & Favour & \\
\hline
\end{tabular}

(b)

FIGURE 3: Comparison of treatment duration (a) and mechanical lithotripsy (b) using rate of EPLBD and EST treatment. 


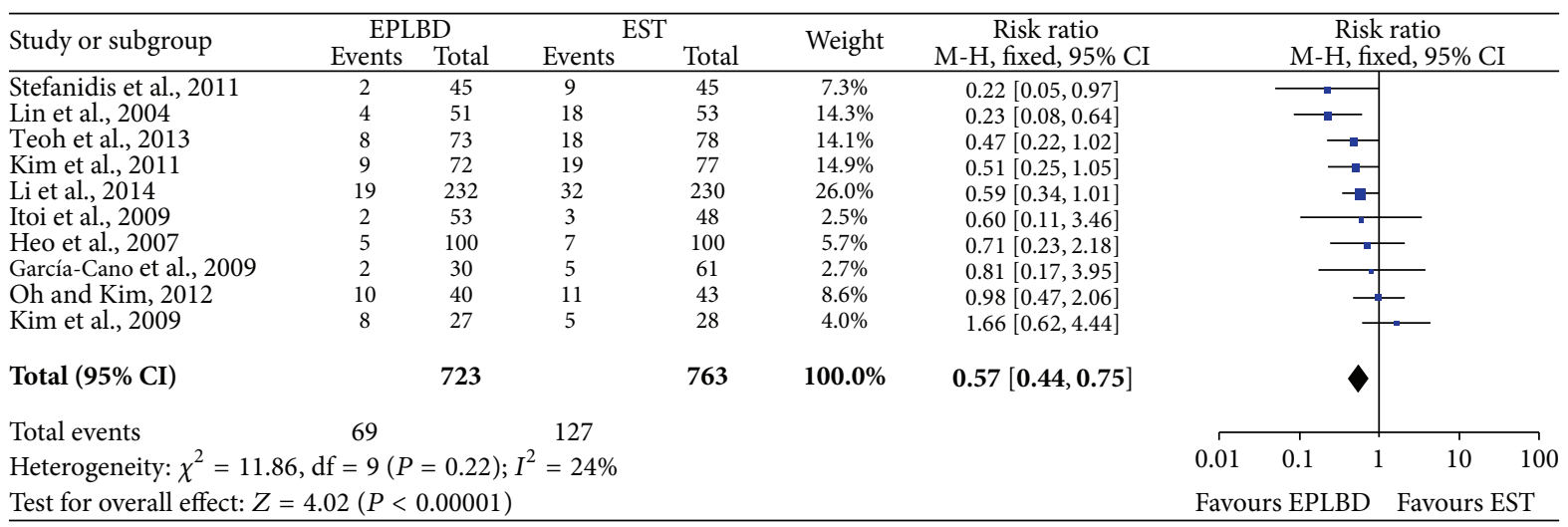

(a)

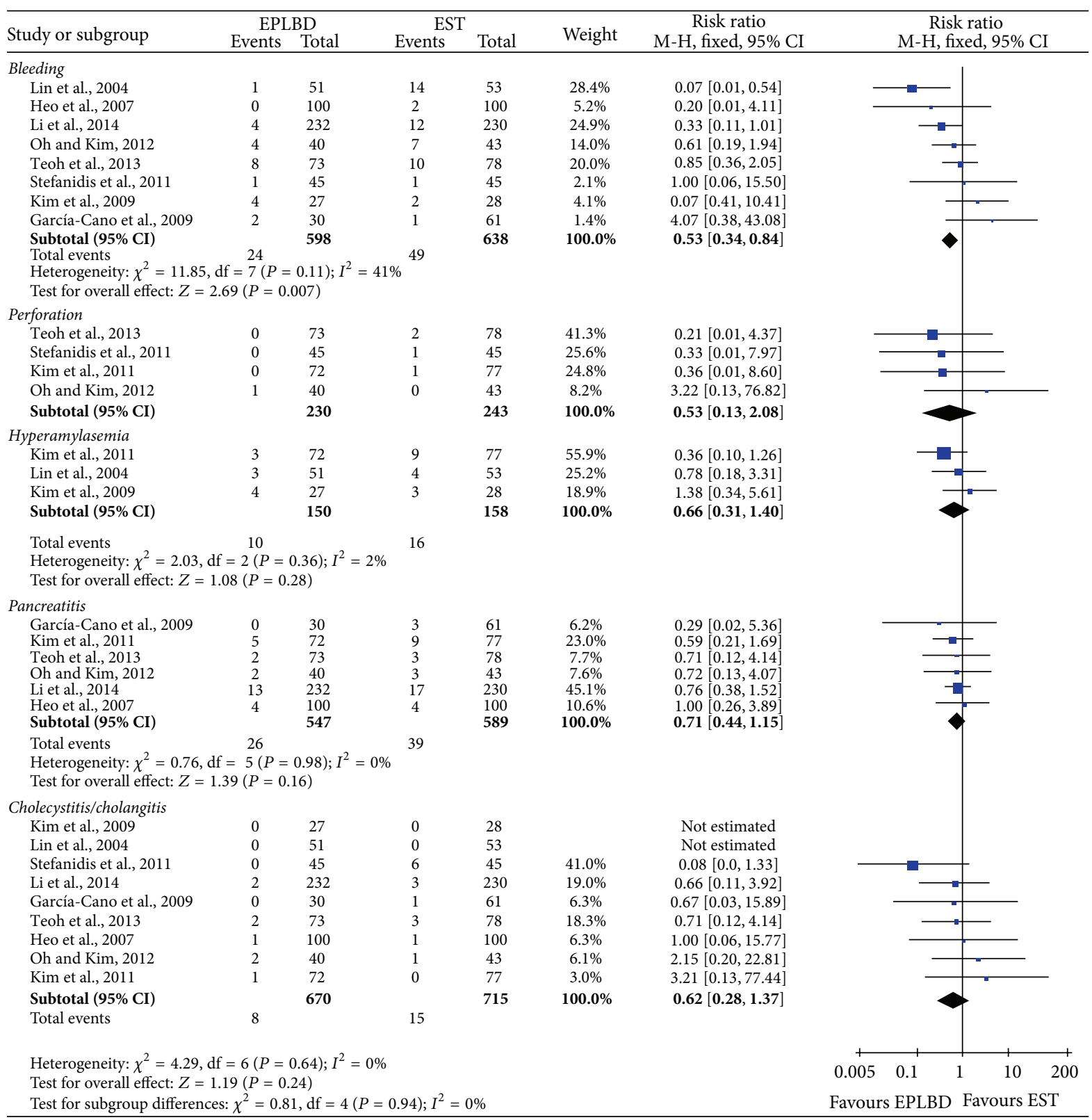

(b)

FIGURE 4: Comparison of overall complications rate (a) and each complications rate (b) of EPLBD and EST treatment. 
effect model was used for the meta-analyses. EPLBD showed obvious overall complications rate $(\mathrm{RR}=0.57,95 \% \mathrm{CI}=0.44 \sim$ $0.75, P<0.0001$; Figure 4(a)) and more serious bleeding $(\mathrm{RR}=0.53,95 \% \mathrm{CI}=0.34 \sim 0.84, P=0.007$; Figure $4(\mathrm{~b}))$ than EST, while there were no significant differences between these two treatments for perforation $(\mathrm{RR}=0.36,95 \% \mathrm{CI}=$ $0.13 \sim 2.08, P=0.36)$, hyperamylasemia $(\mathrm{RR}=0.66,95 \% \mathrm{CI}$ $=0.31 \sim 1.40, P=0.28)$, pancreatitis $(\mathrm{RR}=0.71,95 \% \mathrm{CI}=$ $0.44 \sim 1.15, P=0.16)$, and cholecystitis/cholangitis $(\mathrm{RR}=0.62$, 95\% CI $=0.28 \sim 1.37, P=0.24$ ) (Figure 4(b)).

\section{Discussion}

EST used to be the most commonly used treatment for the removal of bile duct stones. Nevertheless, it is commonly reported that EST could induce substantial procedure associated risks, such as increased incidence of ascending cholangitis [6]. Endoscopic papillary balloon dilatation uses a small balloon catheter, while EPLBD uses a larger balloon $(>12 \mathrm{~mm})$ after the mid-incision EST to remove large common bile duct stones. EPLBD would theoretically combine the advantages of balloon dilation and sphincterotomy by increasing stone extraction efficacy while minimizing complications of them. We performed this meta-analysis to compare the effect of EST and EPLBD for common bile duct stones. Even no significant difference existed in the overall stone removal rate, but, for patients with stones $>10 \mathrm{~mm}$ in diameter, EPLBD could give better overall stone removal rate; however, this treatment needs more duration and will induce higher mechanical lithotripsy using rate with more serious overall complications rate and bleeding, compared with EST. The result was consistent with the study of Fujita et al. [21]. Nevertheless, many studies have recently proposed that EPLBD will not cause complications if performed under strictly established guidelines [22]. Thus, it is of great importance to follow the guidelines during the treatment of EPLBD.

We reviewed previous meta-analysis and found that patients received EPLBD therapy which was associated with shorter length of hospitalization, whereas there was no significance for clearance rates and morbidity/mortality [4]. However, these conclusions may be unreliable, because only 2 included trials reported these outcomes. The current study is based on 10 prospective studies, which are potentially more robust than previous meta-analysis.

There are few limitations of our current study: (1) not all the included literatures studied all the assessment parameters, such as complete stone removal rate in 1st session and treatment duration; (2) the trials adapted different design, including D, S, R, and R; (3) we did not conduct sensitive analysis to test the reliability of the results.

In conclusion, the EPLBD treatment needs more treatment duration and mechanical lithotripsy using rate compared to EST, but, for patients with stones $>10 \mathrm{~mm}$ in diameter, EPLBD could give better overall stone removal rate. What is more, EPLBD would produce obvious overall complications rate and bleeding, compared with EST.

\section{Conflict of Interests}

The authors declare that there is no conflict of interests regarding the publication of this paper.

\section{References}

[1] E. S. J. Clayton, S. Connor, N. Alexakis, and E. Leandros, "Metaanalysis of endoscopy and surgery versus surgery alone for common bile duct stones with the gallbladder in situ," British Journal of Surgery, vol. 93, no. 10, pp. 1185-1191, 2006.

[2] R. A. Duensing, R. A. Williams, J. C. Collins, and S. E. Wilson, "Common bile duct stone characteristics: correlation with treatment choice during laparoscopic cholecystectomy," Journal of Gastrointestinal Surgery, vol. 4, no. 1, pp. 6-12, 2000.

[3] J. M. Hemli, R. S. Arnot, J. J. Ashworth, A. M. Curtin, R. A. Simon, and D. M. Townend, "Feasibility of laparoscopic common bile duct exploration in a rural centre," ANZ Journal of Surgery, vol. 74, no. 11, pp. 979-982, 2004.

[4] E. H. Phillips, J. Toouli, H. A. Pitt, and N. J. Soper, “Treatment of common bile duct stones discovered during cholecystectomy," Journal of Gastrointestinal Surgery, vol. 12, no. 4, pp. 624-628, 2008.

[5] G. R. Caddy and T. C. K. Tham, "Symptoms, diagnosis and endoscopic management of common bile duct stones," Best Practice and Research: Clinical Gastroenterology, vol. 20, no. 6, pp. 1085-1101, 2006.

[6] J. H. Heo, D. H. Kang, H. J. Jung et al., "Endoscopic sphincterotomy plus large-balloon dilation versus endoscopic sphincterotomy for removal of bile-duct stones," Gastrointestinal Endoscopy, vol. 66, no. 4, pp. 720-726, 2007.

[7] M. Staritz, K. Ewe, and K. H. M. zum Buschenfelde, "Endoscopic papillary dilation (EPD) for the treatment of common bile duct stones and papillary stenosis," Endoscopy, vol. 15, no. 1, pp. 197-198, 1983.

[8] T. H. Baron and G. C. Harewood, "Endoscopic balloon dilation of the biliary sphincter compared to endoscopic biliary sphincterotomy for removal of common bile duct stones during ERCP: a metaanalysis of randomized, controlled trials," The American Journal of Gastroenterology, vol. 99, no. 8, pp. 1455-1460, 2004.

[9] C.-K. Lin, K.-H. Lai, H.-H. Chan et al., "Endoscopic balloon dilatation is a safe method in the management of common bile duct stones," Digestive and Liver Disease, vol. 36, no. 1, pp. 68-72, 2004.

[10] T. Itoi, F. Itokawa, A. Sofuni et al., "Endoscopic sphincterotomy combined with large balloon dilation can reduce the procedure time and fluoroscopy time for removal of large bile duct stones," The American Journal of Gastroenterology, vol. 104, no. 3, pp. 560-565, 2009.

[11] J. García-Cano, L. T. Arana, C. J. Ayllón et al., "Biliary sphincterotomy dilation for the extraction of difficult common bile duct stones," Revista Espanola de Enfermedades Digestivas, vol. 101, no. 8, pp. 541-545, 2009.

[12] H. G. Kim, Y. K. Cheon, Y. D. Cho et al., "Small sphincterotomy combined with endoscopic papillary large balloon dilation versus sphincterotomy," World Journal of Gastroenterology, vol. 15, no. 34, pp. 4298-4304, 2009.

[13] T. H. Kim, H. J. Oh, J. Y. Lee, and Y. W. Sohn, "Can a small endoscopic sphincterotomy plus a large-balloon dilation reduce the use of mechanical lithotripsy in patients with large bile duct stones?" Surgical Endoscopy, vol. 25, no. 10, pp. 3330-3337, 2011. 
[14] G. Stefanidis, N. Viazis, D. Pleskow et al., "Large balloon dilation vs. mechanical lithotripsy for the management of large bile duct stones: a prospective randomized study," American Journal of Gastroenterology, vol. 106, no. 2, pp. 278-285, 2011.

[15] M. J. Oh and T. N. Kim, "Prospective comparative study of endoscopic papillary large balloon dilation and endoscopic sphincterotomy for removal of large bile duct stones in patients above 45 years of age," Scandinavian Journal of Gastroenterology, vol. 47, no. 8-9, pp. 1071-1077, 2012.

[16] A. Y. B. Teoh, F. K. Y. Cheung, B. Hu et al., "Randomized trial of endoscopic sphincterotomy with balloon dilation versus endoscopic sphincterotomy alone for removal of bile duct stones," Gastroenterology, vol. 144, no. 2, pp. 341.e1-345.e1, 2013.

[17] G. Li, Q. Pang, X. Zhang et al., "Dilation-assisted stone extraction: An alternative method for removal of common bile duct stones," Digestive Diseases and Sciences, vol. 59, no. 4, pp. 857864, 2014.

[18] K. F. Schulz and D. A. Grimes, "Allocation concealment in randomised trials: defending against deciphering," The Lancet, vol. 359, no. 9306, pp. 614-618, 2002.

[19] R. DerSimonian and N. Laird, "Meta-analysis in clinical trials," Controlled Clinical Trials, vol. 7, no. 3, pp. 177-188, 1986.

[20] R. DerSimonian and R. Kacker, "Random-effects model for meta-analysis of clinical trials: an update," Contemporary Clinical Trials, vol. 28, no. 2, pp. 105-114, 2007.

[21] N. Fujita, H. Maguchi, Y. Komatsu et al., "Endoscopic sphincterotomy and endoscopic papillary balloon dilatation for bile duct stones: a prospective randomized controlled multicenter trial," Gastrointestinal Endoscopy, vol. 57, no. 2, pp. 151-155, 2003.

[22] Y. H. Youn, H. C. Lim, J. H. Jahng et al., "The increase in balloon size to over $15 \mathrm{~mm}$ does not affect the development of pancreatitis after endoscopic papillary large balloon dilatation for bile duct stone removal," Digestive Diseases and Sciences, vol. 56, no. 5, pp. 1572-1577, 2011. 


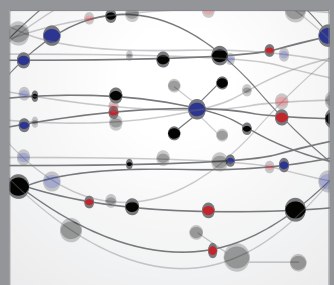

The Scientific World Journal
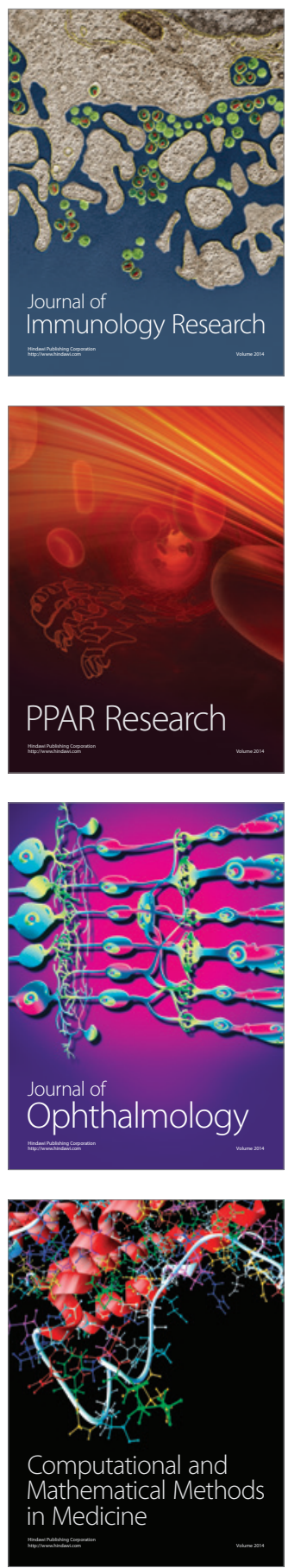

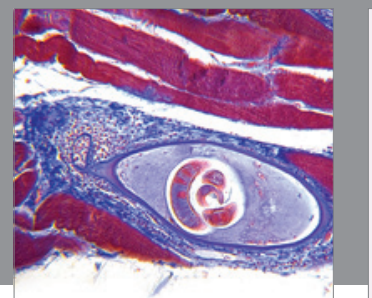

Gastroenterology

Research and Practice
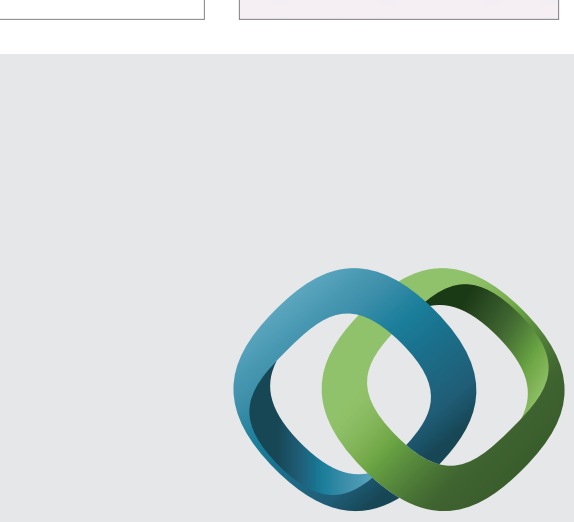

\section{Hindawi}

Submit your manuscripts at

http://www.hindawi.com
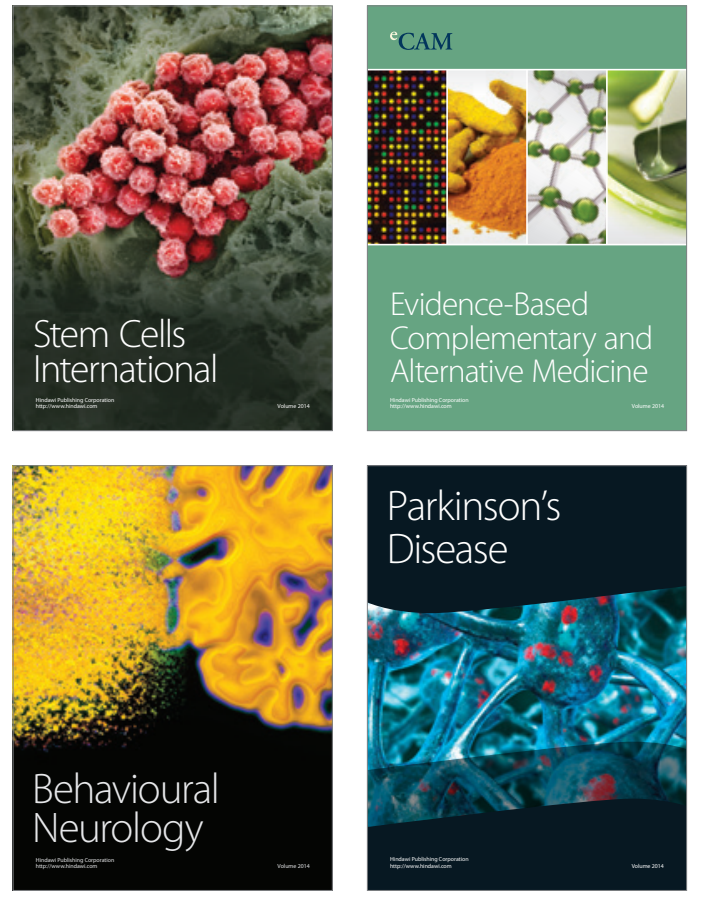
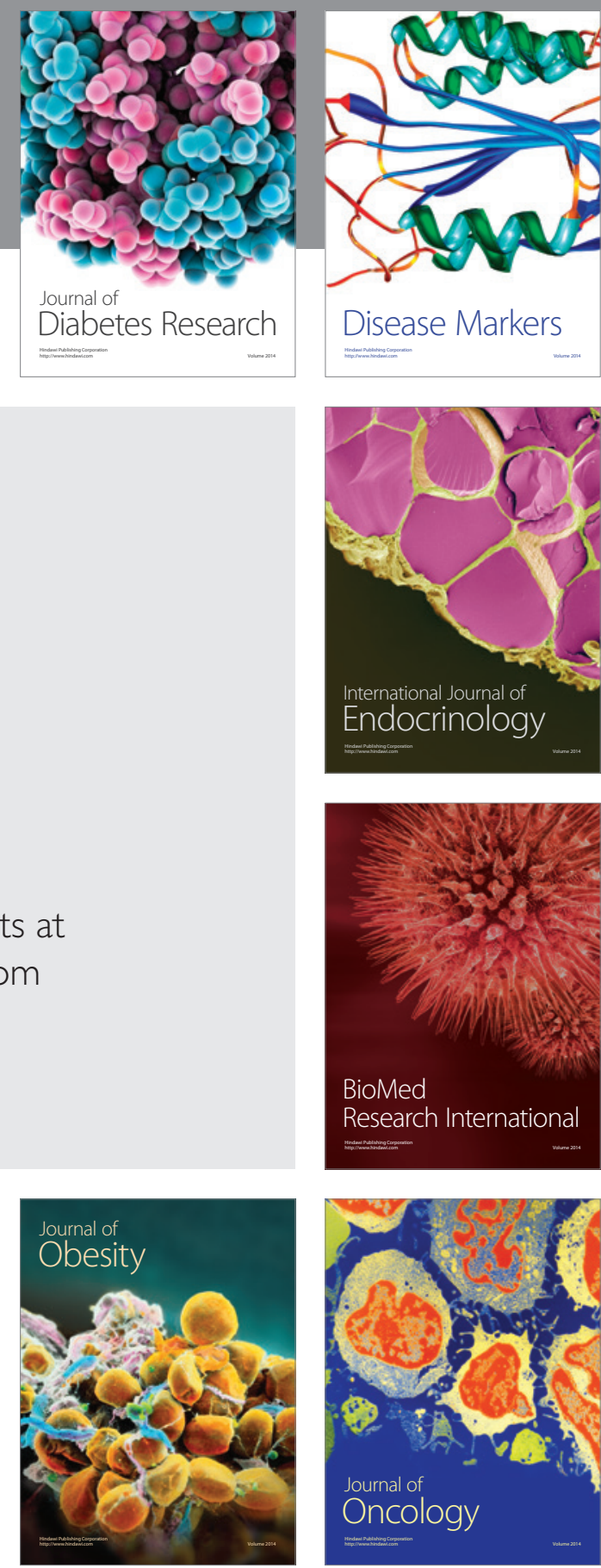

Disease Markers
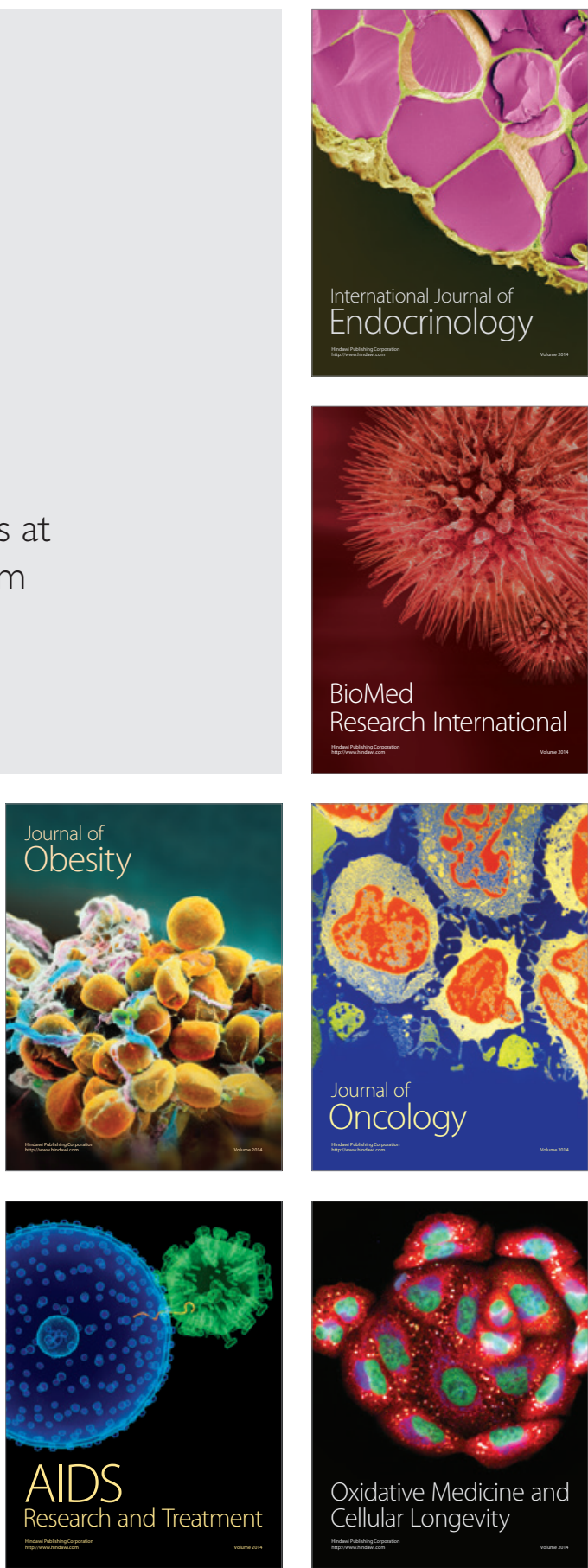